\title{
The TMS Magnesium Committee: Committed to the Advancement of Global Magnesium Technology
}

\author{
Wim H. Sillekens and Eric A. Nyberg
}

Read the full version of this article, including several charts, at http://materialstechnology.tms.org. Further records on the Magnesium Committee are available from the committee homepage (accessible through http://members.tms.org)

The TMS Magnesium Committee was established in 2000 as a spin-off of the Reactive Metals Committee, triggered by the strong global growth of magnesium being used in a variety of structural lightweight applications since the mid-1990s. Since then the committee has seen a distinct development in terms of size, participation, and focus. Particular growth has been seen in the committee's two main activities: the annual Magnesium Technology symposia and publication in JOM of papers related to magnesium R\&D.

The Magnesium Committee is one of five technical committees acting under the umbrella of the TMS Light Metals Division. The committee, comprising active members of the international magnesium community, gathers each year at the TMS Annual Meeting. Committee officers are the organizers of the Magnesium Technology Symposia. Further, the committee annually names advisors to $J O M$ to develop the technical topics determined by the committee.

The Magnesium Technology Symposium is held each year during the TMS Annual Meeting. This symposium encompasses all aspects of magnesium technology, from primary production to applications and recycling, as well as from basic research to industrialization. Since its inception, the symposium has seen twelve successive annual editions and matching proceed- ings volumes (most of which are still available from TMS as book copies and/or CD ROMs).

Over the years the symposium has gradually expanded, developing into one of the largest regular TMS symposia and yearly gatherings of magnesium specialists in the world. The early editions were mainly concerned with technological issues related to metal production and the manufacturing of magnesium components, most notably for automotive applications. At that time, typical topics were casting, coatings, and joining. More recently, however, fundamental scientific aspects are increasingly addressed, including such topics as deformation mechanisms and computational thermodynamics. In addition, emerging applications are explored such as for lightweight armor and biodegradable implants. Alloy development (such as for high-temperature applications) and ecological topics (such as the reduction of green-house gas emissions) have also been discussed throughout the years.

Initially, the number of contributions was quite steady, but as of 2005 when parallel sessions were introduced this number rose steeply. Contributing countries can roughly be divided into two categories, depending on if their market emphasis is on magnesium supply (e.g., China and Israel) or consumption (e.g., Germany, Japan and the United States). The largest share of the proceedings publications comes from the United States, Australia, Canada, China, Germany, Israel, Japan, and South Korea. Overall, the United States accounts for roughly a quarter of all abstracts and papers to date, followed by Canada (14\%), China (11\%) and Germany (10\%). Notably, the symposium participation also reflects the market changes that the magnesium sector has seen over the last decade, the most pronounced example being the large increase in Chinese contributions along with the country's development of primary and alloy production during the more recent years.

The second major activity of the committee is sponsoring JOM technical topics, with each issue targeting a specific theme. To date, 46 papers have been published under the following themes: automotive applications; production, properties and markets; hightemperature magnesium; wrought alloys and processes; magnesium alloys; magnesium; fundamental research; phase diagrams and solidification; phase diagrams and solidification: part 2; magnesium sheet processing; and biomedical applications of magnesium.

The Magnesium Committee has demonstrated its viability to contribute to the global advancement of magnesium technology over the past twelve years and is committed to further pursue this goal for the years to come. TMS members with an interest to participate in the committee are advised to contact one of the authors of this communication or TMS staff.

Wim Sillekens is senior scientist at the Dutch research organization TNO. He can be reached at TNO, P.O. Box $6235,5600 \mathrm{HE}$ Eindhoven, Netherlands; wim.sillekens@ tno.nl. Eric Nyberg is Chief Engineer in the Energy Materials and Manufacturing Department at Pacific Northwest National Laboratory.

\section{Wim H. Sillekens and Eric A. Nyberg are TMS Members!}

To read more about them, turn to page 7. To join TMS, visit www.tms.org/Society/Membership.aspx. 